\title{
Trend of Allergic Rhinitis Post COVID-19 Pandemic: A Retrospective Observational Study
}

\author{
Abhishek Kishore Dayal ${ }^{1}$ (D) Vineet Sinha $^{1}$
}

Received: 7 September 2020/Accepted: 12 October 2020/Published online: 20 October 2020

(C) Association of Otolaryngologists of India 2020

\begin{abstract}
To study, compare and analyse the trend of allergic rhinitis incidence post COVID-19 pandemic in a tertiary care hospital in Patna Bihar. This is a retrospective observational study done at Patna medical college from January to June 2020. The number of patients with signs and symptoms of allergic rhinitis post pandemic (MarchJuly2020) were compared to preceding three months (Jan 2020-March2020). Chi square test was employed to know and infer whether the change in trend of incidence is statistically significant. There is decrease in trend of allergic rhinitis in our study at our centre. $P<.01$. Decrease in pollution due to lockdown and increased use of mask and increase indoor activities may be the reason for decreasing trend of allergic rhinitis.
\end{abstract}

Keywords Allergic rhinitis - Pandemic - ARIA guideline · Pollutant $\cdot$ PM2.5

\section{Introduction}

Allergic rhinitis is the most common manifestation of allergy in the body worldwide [1,2]. Rhazes first described the condition, Clemens Von Pirquet explained the mechanism of immune reaction and Charles Blakeley discovered pollens as cause of hay fever. The diagnostic criteria of allergic rhinitis is vague. Symptom score consisting of QOL score, sleep score used to assess subjective severity. Objective measurement are acoustic rhinometry, rhinomanometry, peak expiratory flow meter. The skin prick test

\footnotetext{
Abhishek Kishore Dayal

akdayal14@gmail.com

Department of ENT, PMCH, Patna, India
}

(48.7\%) has more positive predictive value as an epidemiologic test than then RAST Ig E test. (38.6\%). The earlier classification of seasonal/perennial rhinitis is replaced by intermittent/persistent rhinitis. Various association with hygiene, immunisation, rural enviornment, infection have an inverse relationship with allergic rhinitis. The most common cause of hay fever are pollens from trees [Alder, Birch, Cider, Pinus] grass and weeds. These are wind pollinated pollens and remains in air for longer time owing to its light weight. Hay fever only contributes to what was earlier termed as seasonal allergic rhinitis. Other causes which cause perennial rhinitis include animal dander, dust mites, and moulds. The prevalence of AR varies in various studies and ranges from $10-20 \%$ in America and Europe. About 500 million people are by allergic rhinitis of which 200 million are patient with comorbid asthma. The prevalence of seasonal allergic rhinitis is $1-40 \%$ and perennial rhinitis is $1-13 \%$. Seasonal allergic rhinitis is more common in children while perennial rhinitis in adult.

\section{Theories of Pathogenesis of AR}

Hygiene theory: early infection and sensitisation of allergen shift Th2/Th1 towards Th1 and its cytokine pathway [3].

Immunisation: vaccination with BCG shifts the cytokine pathway towards Th1 [4].

Urban/rural residence: rural tend to be less allergic [5].

Probiotics use and antibiotic misuse [6].

Stress and physical exercise.

Genetic predisposition and family history.

Hypersensitivity and immune dysregulation: IgE mediated type 1 hypersensitivity.

Pollutant and mites exposure [7]. 


\section{Materials and Methods}

This is a retrospective observational study done at Patna medical college from January to June 2020. The number of patients with signs and symptoms of allergic rhinitis post pandemic (March-July2020) were compared to preceding three months (Jan 2020-March2020). Allergic rhinitis is monitored by skin prick test, IgE, S. eosionophilia. ARIA guidelines were employed to grade the severity of symptoms. Chi square test was employed to know and infer whether the change in trend of incidence is statistically significant (Table 1; Fig. 1).

\section{Result}

The number of patients of allergic rhinitis have shown a decreasing trend since the inception of pandemic and lockdown imposition by nearly quartered as compared to immediate preceding three months (Fig. 2).

Chi square test shows that there is statistically significant change in trend of number of cases during the months of April-June [Table 2].

\section{Discussion}

Korsgaard et al. have studied the relation of air pollutant and allergic rhinitis [8-11]. They pointed air pollutant as major cause of allergic rhinitis [12]. The cases of allergic rhinitis seem to have decreasing trend in our study. Many reasons can be sought of to explain such result. There is decrease in level of particulate matter and pollutant in atmosphere owing to complete lockdown in midst of the pandemic. There is a monumental shift in behaviour of our population in using face mask to protect themselves from SARS CoV 2. The AQI of PATNA in lockdown period remained below 50 on an average throughout lock down. PM2.5 concentration dropped by $43 \%$, PM10 by $31 \%, 10 \%$ in $\mathrm{CO}, 18 \%$ in $\mathrm{NO}_{2}$ and negligible change in $\mathrm{SO}_{2}$. Ozone increased $10-20 \%$ in rest of India except eastern India which saw exponential 89\%increase compared to previous

Table 1 Age wise change in incidence of AR during pandemic

\begin{tabular}{lccc}
\hline Age group & Pre-pandemic & Post pandemic & $P$ value \\
\hline $5-20$ & 20 & 6 & .05 \\
$21-35$ & 48 & 12 & .05 \\
$36-50$ & 34 & 8 & .05 \\
$51-65$ & 26 & 4 & .05 \\
Total & 128 & 30 & \\
\hline
\end{tabular}

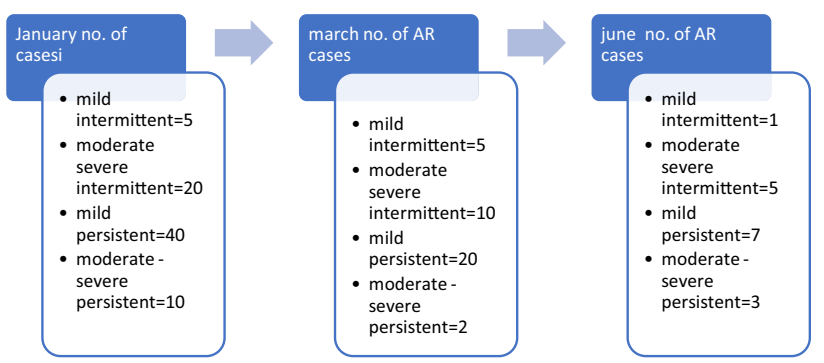

Fig. 1 ARIA classification downgrading of stage

AR incidence trend in COVID pandemic

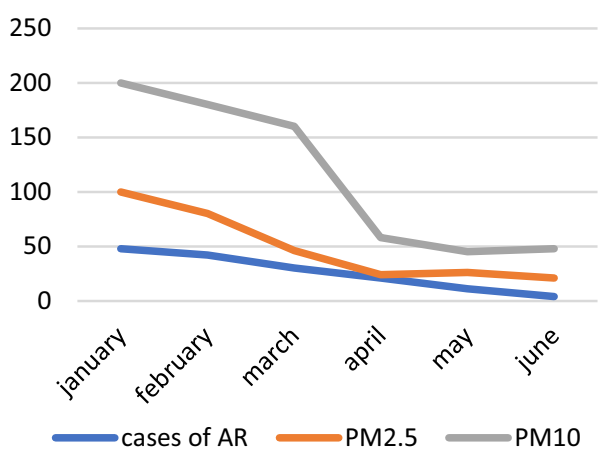

Fig. 2 Trend of pollutant and AR incidence during pandemic

Table 2 Chi square test on changing trend of AR

\begin{tabular}{lllll}
\hline Grade & $\begin{array}{l}\text { Observed cases } \\
\text { in April-June }\end{array}$ & $\begin{array}{l}\text { Expected cases } \\
\text { in April-June }\end{array}$ & $\begin{array}{l}\mathrm{X}^{2}=[\mathrm{O}- \\
\mathrm{E}]^{2} / \mathrm{E}\end{array}$ \\
\hline $\begin{array}{l}\text { Mild } \\
\text { intermittent }\end{array}$ & 12 & 24 & $\begin{array}{c}144 / \\
24=\end{array}$ & .05 \\
$\begin{array}{l}\text { Moderate- } \\
\text { severe }\end{array}$ & 7 & 56 & $49^{2} / 56$ & .05 \\
$\quad \begin{array}{l}\text { intermittent } \\
\text { Mild persistent }\end{array}$ & 10 & & & \\
$\begin{array}{l}\text { Moderate- } \\
\text { severe } \\
\text { persistent }\end{array}$ & 1 & 28 & $18^{2} / 28$ & .05 \\
\hline
\end{tabular}

years. Apart from decrease in pollutant level regular mask use has prevented all allergen to enter and react to nasal mucosa. There is probably some role of decrease junk food consumption during lockdown and improvement in overall general health. The decreasing trend in incidence in these months is not common every year. Grass pollen is common between May to July, tree pollen February to June, and weed between June to September. So indoor activities due to lockdown have drastically cut the number of hay fever cases. This trend need to be studied in bronchial asthma too which will further substantiate our study. However results in our study may not be generalised pan India as the data collected by us is over short period, less sample size and 
Table 3 American AQI

\begin{tabular}{lll}
\hline $\begin{array}{l}\text { AQI } \\
\text { Range }\end{array}$ & Level & Description \\
\hline $0-50$ & Good & Little or no risk \\
$50-100$ & Moderate & \\
$100-150$ & $\begin{array}{c}\text { Unhealthy for sensitive } \\
\text { groups }\end{array}$ & $\begin{array}{l}\text { Sensitive groups } \\
\text { affected }\end{array}$ \\
$150-200$ & Unhealthy & Everyone is affected \\
$200-300$ & Very unhealthy & Emergency condition \\
$300-500$ & Hazardous & Health alert \\
\hline
\end{tabular}

patients of limited geographic distribution of few cities adjoining Patna. Many patient might have not been able to reach hospital owing to lack of transportation due to lockdown. Thus further studies at other centre is required to confirm this trend to be at national or even global level (Table 3).

\section{Conclusion}

There is decreasing trend of allergic rhinitis in current pandemic lockdown period in our study. Further studies with larger sample over larger demography over longer period is required to substantiate it.

\section{References}

1. Meltzer EO, Blaiss MS, Derebery MJ et al (2009) Burden of allergic rhinitis: results from the pediatric allergies in America survey. J Allergy ClinImmunol 124:S43-S70
2. Law M, Morris JK, Wald N, Luczynska C, Burney P (2005) Changes in atopy over a quarter of a century, based on cross sectional data at three time periods. BMJ 330:1187-1188

3. Strachan DP (1989) Hay fever, hygiene, and household size. BMJ 299:1259-1260

4. Shirakawa T, Enomoto T, Shimazu S, Hopkin JM (1997) The inverse association between tuberculin responses and atopic disorder. Science 275:77-79

5. Von-Mutius E, Martinez FD, Fritzsch C, Nicolai T, Roell G, Thiemann HH (1994) Prevalence of asthma and atopy in two areas of West and East Germany. Am J RespirCrit Care Med 149:358-364

6. Alm JS, Swartz J, Lilja G, Scheynius A, Pershagen G (1999) Atopy in children of families with an anthroposophic lifestyle. Lancet 353:1485-1488

7. Korsgaard J, Iversen M (1991) Epidemiology of house dust mite allergy. Allergy 46(Suppl. 11):14-18

8. Yonekura S, Okamoto Y, Horiguchi S et al (2012) Effects of aging on the natural history of seasonal allergic rhinitis in middleaged subjects in South Chiba. JpnInt Arch Allergy Immunol 157:73-80

9. Wachs M, Proud D, Lichtenstein LM, Kagey-Sobotka A, Norman PS, Naclerio RM (1989) Observations on the pathogenesis of nasal priming. J Allergy ClinImmunol 84:492-501

10. Rondón C, Campo P, Togias A et al (2012) Local allergic rhinitis: concept, pathophysiology, and management. J Allergy ClinImmunol 129:1460-1467

11. Settipane RA (2001) Demographics and epidemiology of allergic and nonallergic rhinitis. Allergy Asthma Proc 22:185-189

12. Barnes PJ (2011) Pathophysiology of allergic inflammation. Immunol Rev 242:31-50

Publisher's Note Springer Nature remains neutral with regard to jurisdictional claims in published maps and institutional affiliations. 